\title{
Comparison of stimulated tissue factor expression by brain microvascular endothelial cells from normotensive (WKY) and hypertensive (SHR) rats
}

\author{
David A. Doron ${ }^{a, b}$, Richard M. McCarron c, Eliahu Heldman ${ }^{\text {a,b }}$, Anna-Leena Sirén a, \\ Maria Spatz ${ }^{c}$, Giora Feuerstein ${ }^{d}$, Harvey B. Pollard ${ }^{b}$ and John M. Hallenbeck ${ }^{a, c}$ \\ a Department of Neurology, Uniformed Services University of the Health Sciences, Bethesda, MD 20814-4799 (USA), \\ - Laboratory of Cell Biology and Genetics, National Institute of Diabetes, Digestice, and Kidney Diseases, NIH, Bethesda, MD 20892 (USA), \\ ' Stroke Branch, National Institute of Neurological Disorders and Stroke, NIH, Bethesda, MD 20892 (USA) \\ and "Department of Pharmacology, SmithKline Beecham Laboratories, King of Prussia, PA 19406-0939 (USA)
}

(Accepted 8 September 1992)

Key words: Endothelium; Thromboplastin; Lipopolysaccharide

\begin{abstract}
The amounts of tissue factor (TF) expressed by brain microvascular endothelial cells (BMECs) from normotensive Wistar-Kyoto rats (WKY) and spontaneously hypertensive rats (SHR) were compared after stimulating the cells with different doses of lipopolysaccharide (LPS), thrombin, phorbol myristic acid (PMA), Ca ${ }^{2+}$-ionophore (A23187), or tumor necrosis factor (TNF) and interleukin-1 (IL-1). Treatment of cultured BMECs from WKY and SHR with all of these factors dose-dependently increased their total amount of TF; no substantive differences in the levels of enhanced TF expression were observed between WKY and SHR BMECs. We conclude that stimulated endothelium from rats with hypertension, a major stroke risk factor, is not hyperresponsive with respect to TF expression when compared to normotensive controls.
\end{abstract}

We have previously reported that rats with risk factors for stroke such as hypertension, advanced age and diabetes, develop more stroke events than control rats when the animals are challenged with a single dose of lipopolysaccharide (LPS) ${ }^{10}$. Differences in response to a provocative dose of LPS in vivo between rats with and without risk factors for stroke may depend on the degree of prothrombotic transformation which ultimately occurs in local endothelium ${ }^{4-6}$. This local transformation could be promoted by the risk factor indirectly through accumulation of perivascular macrophages that release cytokines such as tumor necrosis factor- $\alpha$ (TNF- $\alpha$ ) and interleukin-1 (IL-1). These cytokines render endothelium procoagulant ${ }^{4,5.7}$ and increase cellular adhesion ${ }^{26}$. Another possibility is that the sensitivity to different endothelial cell (EC) activators of hemostasis such as IL-1, TNF- $\alpha$ and LPS has been enhanced by the risk factor acting directly on the endothelium. It would be consistent with the latter possibility if the response of brain EC from hyperten- sive rats to LPS, IL-1 and TNF- $\alpha$ were to be an enhanced expression of tissue factor (TF) compared to that of brain ECs from normotensive rats.

TF is a $50 \mathrm{kDa}$ phospholipid-protein complex that triggers blood coagulation in association with factor VIl via the extrinsic pathway ${ }^{22}$. It is known to be constitutively synthesized by a variety of cells including fibroblasts $^{15,16}$, macrophages ${ }^{2,23}$, smooth muscle cells $^{15,16}$ and $\mathrm{EC}^{6,14,16,21}$. In addition, numerous studies have shown that LPS ${ }^{6.14,21}$, TNF- $\alpha^{3.7,24}$, and IL-1 $1^{3.25}$, increase $\mathrm{TF}$ synthesis and expression in a variety of cells in culture.

In the present paper, we tested the hypothesis that the differences in stroke events between normotensive and hypertensive rats observed after LPS treatment in vivo " may in part be due to differences (as a result of the hypertension) in the reactivity of their brain ECs to prothrombotic mediators such as LPS, IL-1 and TNF- $\alpha$. Therefore, we have compared the effects of these factors on TF expression by brain microvascular EC 
(BMEC) isolated from WKY (normotensive) and SHR (hypertensive).

BMEC were isolated following the procedures described by Williams et al. ${ }^{27}$ with some modifications?. For each preparation, five (16-22-week-old) WKY and SHR rats were utilized and isolated BMECs were plated in 24-well tissue culture plates precoated with Matrigel (Collaborative Research, Bedford, MA) and incubated at $37^{\circ} \mathrm{C}$ in a humidified, $5 \% \mathrm{CO}_{2}$ atmosphere; media was changed after $24 \mathrm{~h}$ and then every 3 days. The viability of the cells was tested at the end of the preparation by a Trypan blue exclusion technique'. Cultures were characterized by staining with antibodies to the endothelial cell-specific marker, von Willebrand (FVIII-related) antigen and the astrocyte-specific marker glial fibrillary acidic protein (GFAP), and examined by indirect immunofluorescence microscopy as previously described ${ }^{18}$. Cell numbers in cultures were quantitated by a fluorometric assay as previously described ${ }^{17}$. The Hoechst 33258 (Hoefer Scientific Instruments; San Francisco, CA) was used as a fluorescent probe, and fluorescence was measured in a Perkin Elmer LS-5 fluorescence spectrophotometer set to 365 $\mathrm{nM}$ excitation and $458 \mathrm{nM}$ emission. The measured amount of total DNA was then converted to cell numbers by assuming $6 \mathrm{pg} D N A /$ cell $^{13}$. It was noted that Matrigel, when fresh, contains DNA but the DNA becomes hydrolyzed and disappears during the initial 24-48 $\mathrm{h}$ of plating.

Experiments were performed 10-18 days after the initial preparation. After this time, the media was removed, and $1 \mathrm{ml}$ of either the same media (control) or LPS $(0.01,1$ or $100 \mu \mathrm{g} / \mathrm{ml})$ (E. coli O111:B4; Sigma), thrombin (1 or $10 \mathrm{U} / \mathrm{ml})$, A23187 $(10 \mu \mathrm{M})$, PMA $(100 \mathrm{nM})$, or TNF $(5 \mathrm{U} / \mathrm{ml})$ and $\mathrm{IL}-1(20 \mathrm{U} / \mathrm{ml})$ was introduced. Incubation was carried out for $30 \mathrm{~min}$, $1 \mathrm{~h}, 4 \mathrm{~h}$, or $8 \mathrm{~h}$ at $37^{\circ} \mathrm{C}$ in a humidified atmosphere in $5 \% \mathrm{CO}_{2}$. After the experiment, the cells were gently washed twice with Tris/saline buffer, and the plates were frozen at $-80^{\circ} \mathrm{C}$.

Tissue factor activity was estimated by a two-stage amidolytic assay using purified factors $X$ and VII (Sigma) as previously described ${ }^{15,25}$. Briefly, BMEC were submitted 3 times to a freeze and thaw cycle and were pipetted $(100 \mu$ !) into plastic tubes and placed in a water bath at $37^{\circ} \mathrm{C}$. TF activity was assessed by incubation $\left(37^{\circ} \mathrm{C}, 5 \mathrm{~min}\right)$ with $200 \mu \mathrm{I}$ mixture of factor $X(300 \mathrm{nM})$ and factor VII $(0.5 \mathrm{nM})$ in $20 \mathrm{mM}$ Tris ( $\mathrm{pH}$ 7.4), $135 \mathrm{mM} \mathrm{NaCl}$, and $0.5 \% \mathrm{BSA}$ followed by addition of $100 \mu \mathrm{l}$ of $25 \mathrm{mM} \mathrm{CaCl}$. Factor Xa amidolytic activity was assessed by monitoring the hydrolysis (increase in absorbance at $405 \mathrm{~nm}$ ) of the synthetic peptide Bz-Ile-Glu-Arg-p-nitronilide (S-2222, KabiVitrum).
Under these conditions, factor Xa formation was linear and limited only by the amount of TF present. TF concentration was determined from a standard curve created by serial dilutions of rabbit brain TF (Sigma).

A one-stage clotting (plasma recalcification) assay using either pooled normal plasma (PNP) or factor VII-deficient plasma (George King Bio-Medical, Overland Park, KS) was performed as previously described ${ }^{4,14}$. Similar assays were performed using rabbit brain TF (Sigma) and rat brain TF (saline extract of rat brain homogenate ${ }^{12}$ ) incubated with indicated concentrations of phospholipase-C (PHL-C; Sigma) or Con-A (30 $\mathrm{min}, 37^{\circ} \mathrm{C}$ ), which inhibit TF procoagulant activity 2,8,14. The time to form a clot was monitored with a Fibrometer; one unit of TF was defined as the amount of TF required to generate a thromboplastin time equal to $40 \mathrm{~s}$.

The final BMEC preparation consisted of small groups of cells in the form of microvessel fragments and some single EC. In recent experiments, we have demonstrated by means of total DNA per well quantification, that approximately $10^{4}$ cells were seeded per well and that our plating method permits homogeneous plating with no significant difference in the amount of DNA between wells. Viability of the cells was consistently more than $80 \%$ as assayed on an intermittent basis by the Trypan blue exclusion method. Analysis of BMEC cultures by indirect immunofluorescence microscopy revealed that $>95 \%$ of cultured cells were routinely positive for FVIII-related antigen and < $2 \%$ stained positively for GFAP.

The one-stage clotting times of factor VII-deficient plasma and PNP in the presence of different serially diluted concentrations of rat TF were compared. Clotting times generated by TF ( 1 and $0.1 \mu \mathrm{g} / \mathrm{ml})$ mixed with factor VII-deficient plasma were much longer (10 $\mathrm{s}$ and $135 \mathrm{~s}$, respectively) than those mixed with PNP (40 $s$ and $65 \mathrm{~s}$, respectively). The same dependence on factur VII was found with the amidolytic assay, where almost no TF activity was observed when rat TF was tested with only factor $X\left(O . D ._{405} \mathrm{~nm}=0.090\right)$ as opposed to factors $X$ and VII (O.D. $405 \mathrm{~nm}=0.725)$. Moreover, PHL-C (10-100 $\mu \mathrm{g} / \mathrm{ml})$ and Con A (40-200 $\mu \mathrm{g} / \mathrm{ml})$ dose-dependently inhibited both rabbit and rat TF procoagulant activity in the one-stage clotting assay (results not shown).

When BMEC from WKY and SHR were incubated for $8 \mathrm{~h}$ with different doses of LPS, both WKY and SHR BMEC dose-dependently increased their total amount of TF (Fig. 1). This effect reached significance at $1 \mu \mathrm{g} / \mathrm{ml}$ and $100 \mu \mathrm{g} / \mathrm{ml}(P<0.01)$. However, there were no significant differences in the amount of TF expressed by WKY and SHR BMECs. Treatment with 
$100 \mu \mathrm{g} / \mathrm{ml}$ LPS for $1 \mathrm{~h}$ and $4 \mathrm{~h}$ also resulted in lesser though significant levels of TF release from both SHR and WKY EC; no reproducibly significant differences were observed between SHR or WKY BMECs.

The ability of factors other than LPS to enhance expression was also examined. As shown in Table 1, treatment with TNF + IL-1 or thrombin caused significant TF expression by both SHR and WKY BMECs $(P<0.05)$. In additional experiments not reported here, treatment with A23187, PMA, and higher concentrations of thrombin (i.e. $10 \mathrm{U} / \mathrm{ml}$ ) also resulted in enhanced TF expression above background in all BMEC cultures. In the data shown in Table $I$, as well as the data obtained from additional experiments described above, no significant differences were observed between SHR and WKY BMEC cultures.

We show that BMEC from normotensive and hypertensive rats express dose-dependent increments of TF when the cells are stimulated with LPS (Fig. 1), throm-

\section{Effect of LPS on T. Foctor expression by WKY and SHR BMEC}

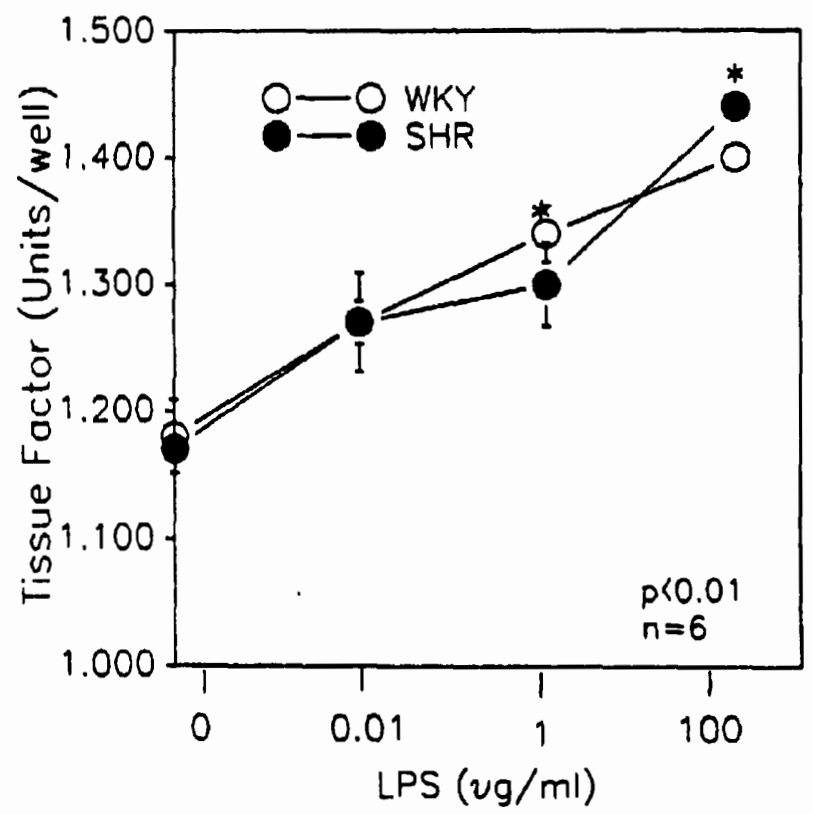

Fig. I. Comparison of TF activity present on BMECs from WHY and SHR rats after LPS treatmenl, BMECs from WKY and SHR rats were isolated and plated onto Matrigel as described before. After 14 days, the cells were incubated with $1 \mathrm{ml}$ of different doses of LPS diluted in M199, $2 \mathrm{mM}$ glutamine. Incubation was for $8 \mathrm{~h}$ at $37^{\circ} \mathrm{C}$ in a humidified incubator after which the plates were placed at $37^{\circ} \mathrm{C}$ in a water bath, and washed 3 times with Tris/saline buffer. After the last wash, the buffer was removed and cells were subjected to 3 freeze and thaw cycles, followed by the amidolytic assay as described in Materials and Methods. The data were interpolated from a standard curve prepared by serial dilutions of Sigma TF. One unit is defined as the amount of TF necessary to form a clot in $40 \mathrm{~s}$ in the one-stage clottiing assay $(n=6 ; * \cong P<0.01)$. The data have been standardized by measuring the amounl of DNA in each well and assuming a DNA concentration equal to $6 \mu \mathrm{g} / \mathrm{cell}^{13}$.
TABLE I

Effects of TNF + IL-1 or thrombin on TF expression by SHR and WKY $B M E C$

\begin{tabular}{|c|c|c|}
\hline \multirow{2}{*}{ Treatment ${ }^{2}$} & \multicolumn{2}{|c|}{ TF Expression ${ }^{b}$} \\
\hline & $\overline{\text { SHR }}$ & $\overline{W K} \bar{Y}$ \\
\hline $\begin{array}{l}\text { Ih } \\
0 \\
\text { TNF + IL-1 } \\
\text { Thrombin }\end{array}$ & $\begin{array}{l}0.056 \pm 0.004 \\
0.072 \pm 0.001 \\
0.072 \pm 0.007\end{array}$ & $\begin{array}{l}0.059 \pm 0.005 \\
0.074 \pm 0.004 \\
0.092 \pm 0.013\end{array}$ \\
\hline $\begin{array}{l}4 h \\
0 \\
\text { TNF + IL-1 } \\
\text { Thrombin }\end{array}$ & $\begin{array}{l}0.078 \pm 0.004 \\
0.101 \pm 0.009 \\
0.211 \pm 0.011\end{array}$ & $\begin{array}{l}0.084 \pm 0.008 \\
0.096 \pm 0.005 \\
0.297 \pm 0.017\end{array}$ \\
\hline
\end{tabular}

bin and the combination of TNF + IL-1 (Table I) as well as PMA and A23187 (results not shown). In all experiments, no significant differences in levels of TF expression were observed between the two groups. Validation of the techniques used to measure TF procoagulant activity from rat vessels consisted of a greatly reduced procoagulant effect in factor VII-deficient plasma, and inactivation of rat TF preparation by PHL- $C^{2,14}$ and Con- $A^{8}$.

We have postulated that risk factors for stroke could create an environment in which the probability of an interaction between perivascular monocytes and macrophages with endothelium via cytokines such as TNF- $\alpha$ and IL-1 is increased ${ }^{1 \mathrm{t}} \cdot 11$. This interaction could increase the probability of local thrombosis or hemorrhage in focal regions of the brain circulatory system and is viewed as equivalent to the preparatory step in the local Shwartzman reaction paradigm ${ }^{19}$. Such an interaction could be intensified by increasing the number of perivascular monocytes and macrophages in extracranial and intracranial vessels and/or rendering these cells hyperresponsive. Conversely, the endothelium lining blood vessels of the brain in animals with risk factors for stroke could be hyperresponsive and express more TF after appropriate stimulation than animals devoid of such risk factors. We have observed that SHR produce more TNF- $\alpha$ in blood and cerebrospinal fluid in response to LPS than their normotensive progenitor, WKY". This suggests that hypertension may be associated with activation of the monocyte/macrophage arm of the postulated interaction. The present study has explored whether the EC of hypertensive animals is sinilarly activaied, and the data suggest that for induction of TF by LPS and other factors used in these experiments, it is not. This finding 
does not, however, exclude the possibility that stroke risk factors are associated with other forms of EC activation, such as adhesion receptor expression or that in vivo stimulation with factors utilized here might produce differential TF expression by EC in the two groups of animals.

The authors wish to thank Dace Klimanis for expert technical assistance.

1 Absher, M., Hemocytometer counting. In P.F. Kruse Jr. and M.K. Patterson Jr. (Eds.), Tissue Culture Methods and Applications, Academic Press, New Yori 1973, pp. 395-397.

2 Amlie, E., Lyberg, T., Kaplun, A., Hetland, O. and Prydz, H., Thromboplastin activity of mouse peritoneal macrophages, Thromb. Res., 24 (1981) 61-71.

3 Archipoff, G., Beretz, A., Freyssinet, J.M., Klein-Soyer, C., Brisson, $\mathbf{C}$. and Cazenave, J.P., Heterogeneous regulation of constitutive thrombomodulin or inducible tissue-factor activities on the surface of human saphenous-vein endothelial cells in culture following stimulation by interleukin-1, tumour necrosis factor, thrombin or phorbol ester, Biochem. J., 273 (1991) 679-684.

4 Bevilacqua, M.P., Pober, J.S., Majeau, G.R., Cotran, R.S. and Gimbrone Jr., M.A. Interleukin 1 (IL-1) induces biosynthesis and cell surface expression of procoagulant activity in human vascular endothelial cells, J. Exp. Mcd., 160 (1984) 618-623.

5 Bevilacqua, M.P., Pober, J.S., Wheeler, M.E., Cotran, R.S. and Gimbrone Jr., M.A. Interleukin-1 activation of vascular endothelium. Effects on procoagulant activity and leukocyte adhesion, Am. J. Pathol., 121 (1985) 394-403.

6 Colucci, M., Balconi, G., Lorenzet, R., Pietra, A., Locati, D., Donati, M.B. and Semeraro, N., Cultured human endothelial cells generate tissue factor in response to endotoxin, J. Clin. Invest., 71 (1983) 1893-1896.

7 Conway, E.M., Bach, R., Rosenberg, R.D. and Konigsberg, W.H., Tumor necrosis factor enhances expression of tissue factor mRNA in endothelial cells, Thromb. Res., 53 (1989) 231-241.

8 Curatolo, L., Alessio, M.G., Casali, B., Falanga, A., Donati, M.B. and Semeraro, N., Procoagulant activity of mouse transformed cells: different expression in freshly isolated or cultured cells (published erratum appears in In Vitro Cell. Dev Biol. 25 (1989) 388], In Vitro Cell. Dew. Biol., 24 (1988) 1154-1158.

9 Doron, D.A., Jacobowitz, D.M., Heldman, E., Feuerstein, G., Pollard, H.B. and Hallenbeck, J.M., Extracellular matrix permits the expression of von Willebrand's factor, uptake of di-Jacetylated low-density lipoprotein and secretion of prostacyclin in cultures of endothelial cells from rat brain microvessels, In Vitro Cell. Dev. Biol., 27A (1991) 689-697.

10 Hallenbeck, J.M., Dutka, A.J., Kochanek, P.M., Sirén, A., Pezeshkpour, G.H. and Feuerstein, G., Stroke risk factors prepare rat brainstem tissues for modified local Shwartzman reaction, Strake, 19 (1988) 863-869.

11 Hallenbeck, J.M., Dutka, A.J., Vogel, S.N., Heldman, E., Doron, D.A. and Feuerstein, G., Lipopolysaccharide-induced production of tumor necrosis factor activity in rats with and without risk factors for stroke, Brain Res., 541 (1991) 115-120.
12 Hjort, P.F., Intermediate reactions in the coagulation of blond with tissue thromboplastin, convertin, accelerin, prothrombinase, Scand. J. Clin. Lab. Invest., 9 (1957).

13 Lehningher, A.L., DNA and the structure of the genetic material. In A.L. Lehningher (Ed.), Biochemistry, 2nd edn., Worth Publishers, New York, 1975, pp. 859-890.

14 Lyberg, T., Galdal, K.S., Evensen, S.A. and Prydz, H., Cellular cooperation in endothelial cell thromboplastin synthesis, $B r$. J. Haematol., 53 (1983) 85-95.

15 Maynard, J.R., Burkholder, D.E. and Pizzuti, D.J., Comparative pharmacologic effects on tissue factor activity in normal cells and an established cell line, Lab. Invest., 38 (1978) 14-20.

16 Maynard, J.R., Dreyer, B.E., Stemerman, M.B. and Pitlick, F.A., Tissue-factor coagulant activity of cultured human endothelial and smonth muscle celle and fibroblasts, Blood, 50 (1977) 387396.

17 McCaffrey, T.A., Agarwal, L.A. and Weksler, B.B., A rapid fluorometric DNA assay or the measurement of cell density and proliferation in vitro, In Vitro Cell. Dev. Biol., 24 (1988) 247-252.

18 McCarron, R.M., Racke, M., Spatz, M. and McFarlin, D.E., Cerebral vascular endothelial cells are effective targets for in vitro lysis by encephalitogenic T lymphocytes, J. Immunol., 147 (1991) 503-508.

19 Movat, H.Z. and Burrowes, C.E., The local Shwartzman reaction. Endotoxin-mediated inflammatory and thrombohemorrhagic lesions. In L.J. Berry (Ed.), Haindbook of Endotoxin, Elsvier, Amsterdam, 1985.

20 Nawroth, P.P., Handley, D.A., Esmon, C.T. and Stem D.M., Interleukin-1 induces endothelial cell procoagulant while suppressing cell surface anticoagulant activity, Proc. Nath Acad.Sci. USA, 83 (1986) 3460-3464.

21 Nawroth, P.P., Stem, D.M., Kisiel, W. and Bach, R., Cellular requirements for tissue factor generation by bovine aortic endothelial cells in culture. Thromb. Res., 40 (1985) 677-691.

22 O'Brien, D.P. The molecular biology and biochemistry of tissue factor, Baillieres. Clin. Haematol., 2 (1989) 801 -820.

23 Rothberger, H., McGee, M.P. and Lee, T.K., Tissue factor activity. A marker of alveolar macrophage maturation in rabbits. Effects of granulomatous pneumnnitis, J. Clin. Invest., 73 (1984) 1524-1531.

24 Scarpati, E.M. and Sadler, J.E., Regulation of endothelial cell coagulant properties. Modulation of tissue factor, plasminogen activator inhibitors, and thrombomodulin by phorbol 12-myristate 13-acetate and tumor necrosis factor [published erratum appears in J. Biol. Chem., 265 (1990) 14696], J. Biol. Chem., 264 (1989) 20705-20713.

25 Stem, D.M., Bank, I., Nawroth, P.P., Cassimeris, J., Kisiel, W., Fenton I] J.W., Dinarello, C., Chess, L. and Jaffe, E.A., Self-regulation of procoagulant events on the endothelial cell surface, $J$. Exp. Med., 162 (1985) 1223-1235.

26 Wankowicz, Z., Megyeri, P. and Issekutz, A., Synergy between tumour necrosis factor aipha and interleukin- 1 in the induction of polymorphonuclear leukocyte migration during inflammation, $J$. Leukoc. Biol., 43 (1988) 349-356.

27 Williams, S.K., Gillis, J.F., Matthews, M.A., Wagner, R.C. and Bitensky, M.W., Isolation and characterization of brain endothelial cells: morphology and enzyme activity, J. Neurochem., 35 (1980) 374-381. 